\title{
REFERENCIAÇÂOO E HUMOR NO ENSINO DE LÍNGUA PORTUGUESA
}

\section{REFERENCING AND HUMOR IN PORTUGUESE LANGUAGE EDUCATION}

\author{
Leonor Werneck dos Santos ${ }^{2}$ \\ Fernanda Andrade ${ }^{3}$
}

\begin{abstract}
RESUMO: Neste artigo, discutimos como as estratégias de referenciação, em especial as anáforas diretas, colaboram na construção de sentido do humor em crônicas de Luiz Fernando Verissimo. Além de analisar a crônica "Inimigos", mostrando o papel das anáforas diretas, discutimos como essa análise pode ser útil no ensino, principalmente porque textos de Verissimo costumam figurar em diversos livros didáticos de Língua Portuguesa.

Palavras-chave: Referenciação. Crônica. Humor. Ensino de Língua.
\end{abstract}

ABSTRACT: In this article, we discuss how some referencing strategies, especially direct anaphora, collaborate in the construction of sense of humor in the chronicles of Luiz Fernando Verissimo. We analyze the chronicle "Enemies", showing the role of direct anaphora, and we discuss how this analysis can be useful in Portuguese language teaching, as Verissimo texts are often included in several textbooks.

Keywords: Referencing. Chronicle. Humor. Language teaching.

\section{Introduçăo}

Quando se fala em ensino de Língua Portuguesa, é comum discutir a importância da compreensão de textos variados para formar leitores críticos e ampliar a competência linguística e comunicacional dos alunos. Para esse processo de leitura, o aluno precisa acionar conhecimentos prévios que colaborem para a construção dos sentidos. Porém, em alguns textos, a percepção de algumas estratégias pode ser

\footnotetext{
${ }^{1}$ Artigo recebido em 27/02/2019 e aprovado em 28/05/2019.

2 Doutora pela UFRJ; Professora de Língua Portuguesa da UFRJ; Membro do GT da ANPOLL Linguística de Texto e Análise da Conversação; E-mail: leonorwerneck@gmail.com

${ }^{3}$ Mestranda pela UFRJ; Professora de Língua Portuguesa da rede particular do Rio de Janeiro; Email: feandrade.souza@hotmail.com
} 
bastante complexa; é o que acontece com os recursos que provocam o humor em crônicas.

Neste artigo, pretendemos colaborar com o ensino de Língua Portuguesa, analisando uma crônica de Luiz Fernando Verissimo, autor cujos textos frequentemente circulam na internet ou em livros didáticos. As crônicas de Verissimo caracterizam-se pelo relato de fatos cotidianos, cercados de crítica social mesclada a um humor fino e, por vezes, sutil. Para perceber esse humor e essa crítica, é necessário entender alguns recursos utilizados nos textos, dentre eles as estratégias de referenciação.

Assim, analisaremos aqui as anáforas diretas referentes aos personagens principais da crônica "Inimigos", de Verissimo, demonstrando como esse recurso atua na construção de sentido do humor. Com essa proposta de leitura da crônica, esperamos colaborar para o ensino, de maneira a tornar mais claro "o que constitui o humor" - pergunta recorrente em questões de livros didáticos e provas.

\section{Texto, leitura e referenciaçăo}

O ensino de língua vem passando por modificações em relação a algumas práticas pedagógicas e a alguns conceitos que vêm se modificando ao longo dos anos como uma maneira de incentivar uma prática mais produtiva e com base no estudo do texto. Conforme alguns estudiosos da área, dentre eles Koch e Elias (2003, 2006), Koch (2002, 2014 [1989], Marcuschi (2006, 2010), Cavalcante (2010), a noção de texto, atualmente, pode ser entendida como um conceito que vai além das formas linguísticas organizadas. Marcuschi (2008, p.243) caracteriza o texto como "sistemas instáveis e sua estabilidade é sempre um estado transitório de adaptação a um determinado objeto e contexto". Já Cavalcante (2012, p.19) destaca o processo de interação, em que "os sujeitos são vistos como agentes sociais que levam em consideração o contexto sociocomunicativo, histórico e cultural para a construção dos sentidos e das referências dos textos".

Assim, na Linguística de Texto (LT), atualmente, o conceito de texto recebe um tratamento de ordem sociocognitiva e interacionista, ou seja, é importante que os interlocutores reconheçam não só os aspectos formais e linguísticos, mas também as intencionalidades. Considerando que o texto é visto como lugar de interação, da mesma forma o processo de leitura é uma prática social que envolve observação das operações 
linguístico-discursivas utilizadas na produção de sentido. Ler um texto não se restringe à decodificação de sua estrutura linguística, mas necessita de mobilização tanto de aspectos linguísticos quanto de estratégias de ordem cognitivo-discursiva, no intuito de levar o leitor a um levantamento de hipóteses, participando na compreensão e na construção de sentidos (SANTOS, 1994).

Nessa perspectiva sociointeracional da linguagem, os sujeitos são vistos como ativos, e a leitura se realiza no processo de interação e de produção de sentidos. 0 processamento do texto exige a participação e a interação dos enunciadores, acionando diversos conhecimentos de ordem textual, cultural e cognitiva para produzir sentido, porém essa relação depende de inferências. Por isso, a importância da referenciação, definida por Koch e Marcuschi (1998) como uma atividade discursiva que compreende uma visão de instabilidade dos referentes, que são construídos de acordo com as escolhas dos sujeitos no momento da interação.

De acordo com Koch (2002), os objetos de discurso são construídos no interior do discurso e são entidades dinâmicas que podem ser alteradas, reativadas ou recategorizadas, construindo ou reconstruindo sentido, o que contribui para a progressão textual e, muitas vezes, influencia na interpretação do texto. Portanto, "a realidade é construída, mantida e alterada não somente pela forma como nomeamos o mundo, mas, acima de tudo, pela forma como sociocognitivamente interagimos com ele" $\mathrm{KOCH}$, 2002, p.79). Sendo assim, os referentes são construídos no texto, o que evidencia que a linguagem não é um simples sistema de etiquetagem quando se refere a algo do mundo, o que ocorre é que os objetos do discurso se (re)constroem em práticas discursivas, sociocognitivas, cultural e historicamente situadas.

Para autores como Koch e Marcuschi (1998), Koch (2003, 2014 [2008] e Koch e Elias (2014 [2006]), a construção da referenciação acontece por estratégias de introdução, retomada e desfocalização. A primeira é a inserção de um objeto, mencionado pela primeira vez, e que passa a ser o foco no texto. A retomada é a reativação desse objeto que já está presente por meio de uma forma referencial. Já a desfocalização ocorre quando se introduz um novo objeto que acaba ocupando a posição de destaque. No entanto, o objeto mencionado anteriormente continua disponível, podendo ser reativado a qualquer momento. Dessa forma, podemos perceber o quão 
complexo pode ser o processo de compreensão do texto devido aos acréscimos de novas informações referentes ao inserido na introdução.

A escolha por determinados referentes na construção do texto envolve também fatores extralinguísticos (interlocutor, intenção comunicativa e contexto), o que colabora para criar vários efeitos de sentido, como "criticar algo, ressignificar um termo em evidência, causar humor" (COLAMARCO, 2014, p. 52). Assim, os processos referenciais deixam de ser compreendidos como elementos identificados por equivalência direta e são vistos como elementos que dependem de relação entre linguagem e sujeito.

No processo de progressão textual acionado pela referenciação, é importante observar a recategorização, que contribui para a construção do sentido, tendo em vista que as novas formas ativam certos conhecimentos que serão partilhados por meio de características dos referentes e que podem levar o interlocutor a construir uma nova imagem do referente introduzido. Segundo Koch (2005, p. 35), "Trata-se, em geral, da ativação, dentre os conhecimentos culturalmente pressupostos como compartilhados, de características ou traços do referente que devem levar o interlocutor a construir dele determinada imagem(...)".

De maneira semelhante Cavalcante, Custódio Filho e Brito (2014, p.156) destacam que,

Em todo o texto, o locutor constrói a referência com base numa interpretação do mundo real, recategorizando a informação precedente ao acrescentar novas predicações, disponíveis, em diferentes graus, no conhecimento das pessoas, à medida que transcorre a interação.

Portanto, há diferentes processos referenciais que os participantes da interação utilizam para construção de sentidos e para a coerência dos textos produzidos. Neste artigo, trataremos apenas das anáforas diretas $(A D)$, retomada direta ou parcial de um mesmo objeto de discurso. Ciulla e Silva (2008) e Cavalcante (2011) ressaltam que nas AD também pode ocorrer um apelo à memória discursiva e que pode haver um referente reformulado por meio de informações inferenciais, o que intensifica a ideia de que a construção da referência ocorre por meio de uma complexa relação de inferências. 
Segundo Santos e Cavalcante (2014, p. 227), a correferencialidade é uma característica das $A D$, marcadas por expressões pronominais ou nominais: "casos em que há correferencialidade, em que se retoma total ou parcialmente [...] um referente no universo do discurso". Portanto, os objetos de discurso sofrem transformações e recategorizações, e as $A D$ promovem essa reformulação, por meio de mecanismos inferenciais, dependendo das intencionalidades e das características do gênero.

\section{Crônica e humor}

A crônica é um gênero textual que apresenta, em sua composição, fatos relacionados a situações humanas e que pode ser caracterizada como um texto passageiro, de divagação pessoal, que utiliza uma linguagem literária e está ligada a ideia de cotidiano. Sá (1987) e Candido (1992) consideram, em seus estudos, a crônica como um gênero que mistura o caráter jornalístico e literário em sua composição. Ao migrar do jornal para os livros, o registro que era passageiro transformou-se em um texto duradouro.

Para Candido (1992, p.13), a crônica "por meio dos assuntos, da composição solta, do ar de coisa sem necessidade que costuma assumir, ela se ajusta à sensibilidade do dia a dia" e, assim, conquista o público leitor. Para o autor, na crônica, as características atreladas ao jornalismo e sua forma de produção não impedem a relação com a literatura. Já Ritter (2009, p. 10 e 11) defende que a crônica "cumpre com essa função jornalística de entretenimento, e é por isso que também apresenta uma natureza literária, pois o cronista recria o fato cotidiano por meio da leveza, da beleza, da poesia, da crítica, do humor".

Dessa forma, o tom humorístico e, muitas vezes, irônico e despretensioso é uma das características desse gênero. Em relação às crônicas de Luis Fernando Verissimo, observamos que o autor tende a abordar os mais diversos temas, buscando retratar a realidade ou a situação de uma determinada época. Muitas vezes, Verissimo insere o leitor na história, de maneira informal, e utiliza o humor - por vezes irônico ou sarcástico - para retratar diversos assuntos de forma sofisticada, mas com uma linguagem coloquial e elegante, estabelecendo associações com o mundo real.

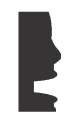


Bosi (1988) explica que o humor está relacionado a situações humanas e que cabe ao criador de uma mensagem com tom humorístico deixar transparecer a impotência da condição humana e revelar problemáticas do comportamento humano. Sendo assim, é comum associar o humor aos defeitos humanos, perceptíveis ou não, e, para efeito humorístico, tornar o exagero e o ridículo algo comum. Para Possenti (1998, p.37), "as piadas só ocorrem num solo fértil de problemas".

Travaglia (1990) e Possenti (1998) apontam diversas situações em que o humor aparece e destacam algumas estratégias linguísticas que o provocam. Segundo Travaglia (1990), em narrativas, uma dessas estratégias é a criação de nomes de personagens ou descrição de personagens que podem ter como função criticar certos comportamentos humanos. Já Possenti (1998, p. 21) sugere que aspectos relativos a "sintaxe, morfologia, fonologia, regras da conversação, inferências, pressuposições etc." , colaboram para o humor, embora também criam efeitos de sentido diversos em textos não humorísticos.

Nessa mesma perspectiva, Propp (1992, p. 32) afirma que a causa do humor pode ser de ordem histórica, nacional, social ou pessoal: "Cada época e cada povo possui seu próprio e específico sentido de humor e de cômico que, às vezes, é incompreensível e inacessível em outras épocas". Sendo assim, em relação ao âmbito sociocultural e histórico, as diferentes camadas sociais de diferentes locais apresentam suas particularidades em relação ao humor e diferentes meios para expressá-lo. Na mesma linha de raciocínio, Possenti (2001, p.72) destaca que "uma língua funciona sempre em relação a um contexto culturalmente relevante e que cada texto requer uma relação com outros textos". Essa afirmação explicaria por que um texto pode provocar riso para um determinado grupo social e não para outro, ou por que pode provocar riso em uma determinada época e não em outra.

Nos textos de Verissimo, é possível perceber as histórias relacionadas à realidade comum das pessoas, normalmente apresentando alguma situação cômica e crítica. Notamos, nas obras do autor, que o humor é muitas vezes uma forma de provocar reflexão sobre certos comportamentos sociais. Sobre a obra desse autor, Konzen (2002, p. 96) destaca que

A comicidade está entre as características constantes em suas narrativas - nas mais inusitadas formas. A 
descontração em falar de qualquer tema e uma visão sólida sobre os fatos revelam análises inteligentes e precisas da vida cotidiana: a arte de Luis Fernando Verissimo reside, fundamentalmente, na capacidade de captar cenas, muitas vezes insignificantes à primeira vista, e torná-las visíveis e risíveis, pelo emprego de recursos diversificados.

Possenti (2010) acredita que o humor pode ser considerado um campo de estudo e pode ser produzido em diversos ambientes, por meio de diferentes organizações textuais, tratando de diferentes temas. Esse fenômeno tem sido visto como uma forma de análise de questões sociais, culturais e que são, portanto, de grande relevância para estudos de cunho psicológico, social, filosófico e também linguístico e textual-discursivo. Além disso, o humor pode estar associado a uma crítica ou denúncia social, abordando situações de preconceito, valores ou estereótipos. Dessa forma, é notável como o humor desempenha um papel social com a função de enfrentar o que já está estabelecido, o que o torna uma fuga para possíveis padrões de comportamento, de ações, de pensamentos e de culturas.

Por fim, notamos que o humor, seja mais sofisticado ou agressivo, lúdico ou sarcástico, é compreendido como uma maneira de discutir, apresentar, denunciar certos conflitos sociais, políticos e culturais, comportamentos sociais, de forma a promover reflexão crítica, sem se prender à censura ou julgamento negativo de determinada época. Por isso, constitui um campo de estudos com muitas possibilidades para os estudos linguísticos.

\section{Anáforas diretas na crônica "Inimigos": um caminho para 0 ensino}

A crônica "Inimigos", de Luis Fernando Verissimo, abaixo transcrita, apresenta a história da relação de um casal após o casamento. Destacamos as anáforas referentes aos objetos de discurso "Norberto" e

"Maria Tereza".

\section{Inimigos}

O apelido de Maria Tereza, para Norberto, era 'Quequinha'. Depois do casamento, sempre que queria contar para os outros uma de sua mulher, o Norberto pegava na sua mão, carinhosamente, e começava: 


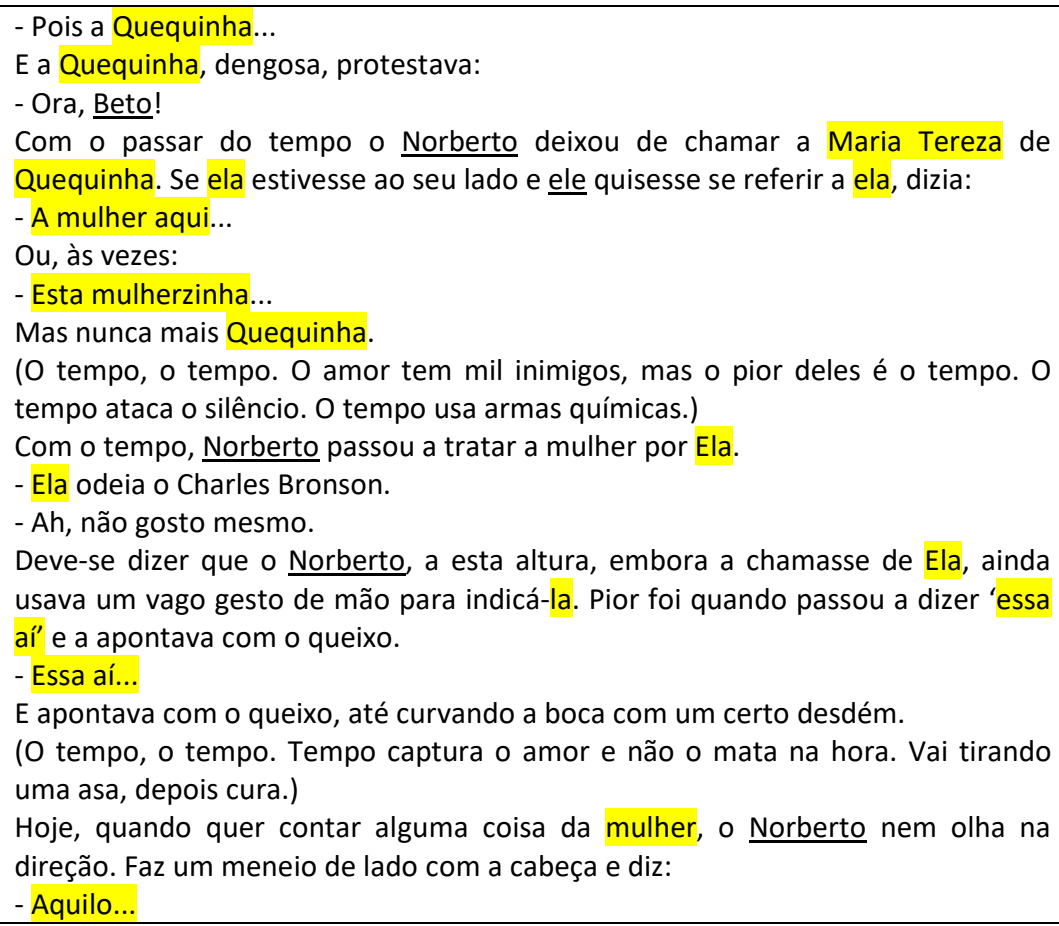

Inicialmente, notamos que o objeto de discurso "Maria Tereza" é retomado por "Quequinha", maneira carinhosa com a qual Norberto se dirige a sua esposa. Podemos observar, nesse caso, que o novo referente não significa apenas uma forma de um personagem se referir a outro, pois há uma representação de valor afetivo entre os personagens, ou seja, o objeto de discurso "Maria Tereza" foi recategorizado pela anáfora direta "Quequinha", em que o uso do diminutivo representa o carinho que existia entre os personagens. Vale acrescentar, ainda, que o uso desse novo referente nos faz inferir sobre o tipo de relação que Norberto e Maria Tereza viviam antes e logo no início do casamento.

Em seguida, "Maria Tereza" é retomada novamente por outra anáfora direta: "sua mulher". É possível perceber, na segunda retomada, o valor de posse presente na expressão. A personagem deixa de ser referida pelo nome ou pelo apelido carinhoso e é destacada por ser a mulher de Norberto.

No decorrer do texto, o uso das anáforas diretas "ela" e "a mulher aqui" mostra, nitidamente, o início de um distanciamento do casal, visto que o personagem Norberto não mais se refere a sua esposa com carinho, mas 
como qualquer mulher. Esse distanciamento é reforçado pelo narrador no momento em que comenta sobre a passagem do tempo e a relação entre casais. Ao utilizar a expressão "a mulher aqui", Maria Tereza deixa de ser uma pessoa especial e se torna, para Norberto, uma mulher sem significado em sua vida.

Em um próximo momento, o objeto de discurso "Maria Tereza" é mais uma vez recategorizado pelo referente "Esta mulherzinha". Nesse caso, o uso do diminutivo sugere uma atitude pejorativa por parte do personagem Norberto ao referir-se a sua esposa. Diferentemente do que ocorre com o uso do diminutivo em "Quequinha", que representa valor afetivo, no caso de "Esta mulherzinha", o diminutivo representa a maneira negativa como a mulher passou a ser tratada pelo marido.

Um maior distanciamento do casal é representado pelo uso do pronome pessoal "Ela" e pela expressão "Essa aí". Vale ressaltar que o pronome "Ela" é muito utilizado para retomar algum termo anteriormente mencionado. No entanto, no exemplo acima, é notável a carga de significado que o termo carrega, visto que o pronome não foi utilizado apenas como uma estratégia de coesão para evitar a repetição, mas para representar, de maneira gradativa, o distanciamento que vem ocorrendo no relacionamento dos dois personagens. Além disso, notamos que a recategorização que acontece com o uso da expressão "Essa aí" indica que a personagem Maria Tereza não é sequer denominada por seu marido, denotando um quase desprezo.

Por fim, como forma de concretizar o fim da relação entre o casal, "Maria Tereza" é retomada como "Aquilo". O uso desse pronome demonstrativo mostra que a personagem passa a não ter nenhum significado para Norberto, torna-se algo sem identificação, sem nome.

Nessa trajetória, notamos que o distanciamento do casal é representado pelo uso das anáforas diretas a cada vez que Maria Tereza é recategorizada; o uso do objeto do discurso "Aquilo", por exemplo, define o fim da relação entre o casal, visto que o homem não enxerga mais a mulher como uma pessoa, mas como algo sem valor para ele. Já o objeto de discurso Norberto é recategorizado apenas como Beto (na fala de sua esposa, no início do casamento) e, posteriormente, pela repetição do nome próprio e do pronome "ele". Essa recategorização aponta para o leitor a 
história do casal na perspectiva do marido, que em nenhum momento é criticado ou "coisificado".

Ao analisarmos essa crônica, notamos que Verissimo apresenta uma crítica social em relação à forma como as pessoas lidam com o casamento, e o processo de referenciação foi essencial para explicitar essa crítica. Como já dito anteriormente, o humor, normalmente, está associado a relações humanas ou a algum aspecto humano, deixando transparecer a impotência do comportamento entre as pessoas e revelando problemáticas desse comportamento.

Um outro aspecto importante a ser apresentado nesse exemplo e também relacionado à questão do humor é o título da crônica, que reafirma e antecipa o distanciamento do casal, mas que não é percebido logo de início. Os leitores podem vir a achar o título incoerente ao iniciarem a leitura da crônica, no entanto, durante o texto, notamos que o casal se distancia a tal ponto de se tornarem inimigos.

Reafirmamos, portanto, que as estratégias de referenciação não são utilizadas de maneira aleatória ou ocasional, mas de forma pensada propositalmente para fornecer determinado sentido ao texto. Nesse caso, o distanciamento entre o casal ao longo da relação entre eles foi provado pela forma como o marido refere-se à mulher no decorrer do casamento. E a repetição apenas do nome do marido e do pronome pessoal "ele" reiteram o ponto de vista de Norberto a respeito da relação.

Em relação ao ensino, além de mostrar essas estratégias referenciais aos alunos, o professor pode analisar a crônica "Inimigos", começando com um debate sobre o título, como atividade pré-textual (SANTOS; CUBA RICHE; TEIXEIRA, 2012), para estimular os alunos a refletirem sobre a temática do texto. Assim, os alunos criarão hipóteses que podem ou não ser confirmadas no decorrer da leitura. Quem seriam os inimigos? Por que são inimigos? O que causou a inimizade? Essas são algumas das perguntas que podem ser feitas em sala de aula.

Além disso, ainda a partir do título, o professor pode discutir com os alunos se um texto com esse título poderia ter marcas de humor. É importante também mostrar aos alunos que humor e riso nem sempre estão associados (cf. SANTOS, 2004), pois é comum os alunos acharem que humor significa "achar graça, gargalhar". Um texto humorístico é aquele que 
subverte as expectativas, acionando uma possibilidade de leitura que nem sempre é explícita, podendo ou não levar ao riso.

Voltando às anáforas, como atividade textual, é interessante mostrar aos alunos (mesmo sem usar nomenclatura) que, embora a cadeia anafórica Maria Tereza>Quequinha>a mulher aqui>essa mulherzinha>ela>essa aí>aquilo mostre elementos correferenciais (que retomam o mesmo referente), a ordem em que esses elementos aparecem no texto é essencial para a compreensão do enredo, para a percepção do desgaste do relacionamento do casal e para a construção do humor. 0 professor pode, ainda, destacar que, nesse caso, o humor advém de uma inversão do final feliz que se espera em histórias de amor, devido ao choque de realidade diante de uma relação amorosa que não devia levar ao riso, mas é apresentada de maneira humorística.

Ao analisar o desenrolar da narrativa, é importante atentar para as pistas textuais que reforçam o afastamento do casal reiterado pelas anáforas. Por exemplo, se no início do relacionamento Norberto pegava carinhosamente a mão de Tereza, ao final ele se refere a ela com um meneio de cabeça, o que reforça seu desdém pela esposa. Dessa forma, pode-se sugerir que os alunos elaborem um quadro e, ao lado de cada anáfora (Quequinha, ela, essa aí, etc.), listem outras pistas ("aponta com o queixo", "Faz um meneio de cabeça", etc.) que reafirmam esse distanciamento do casal, observando essas expressões são cada vez mais negativas à medida em que o tempo passa.

Ainda como atividade textual, o professor pode analisar, junto aos alunos, o efeito de sentido causado com o comentário do narrador que se encontra nos primeiros parênteses do texto, que funciona como uma forma de criticar um comportamento humano: com o aumento da intimidade, da convivência e com o desgaste da relação, as pessoas tendem a ter menos paciência, carinho e cuidado quando estão em um relacionamento. Nesse contexto, o professor pode ainda mostrar que o humor, muitas vezes, está associado à crítica aos comportamentos humanos e solicitar que o aluno identifique qual comportamento está sendo criticado na crônica.

Em seguida, o professor pode incentivar os alunos a identificarem a figura de linguagem presente nas frases "O tempo ataca o silêncio. $O$ tempo usa armas químicas". Essa seria uma questão em que o professor poderia também trabalhar algumas características do gênero textual 
crônica, como o uso da linguagem literária. Aliás, a própria repetição do termo "O tempo", em frases tão curtas com estrutura sintática semelhante (sujeito, verbo, objeto direto), causa um efeito de sentido de ênfase que merece ser discutido.

Finalmente, como atividade pós-textual, esta crônica nos permite refletir sobre a questão da mulher na sociedade. O professor pode propor que o aluno estabeleça um paralelo entre a desvalorização da mulher na sociedade e no próprio relacionamento a dois. Além disso, ainda sobre essa questão, é importante que o aluno perceba a passividade da mulher diante da forma como o homem se referia a ela.

\section{Conclusằo}

Neste artigo, pretendemos mostrar como a análise de uma crônica de Verissimo pode ser levada para a sala de aula para sensibilizar os alunos a respeito de marcas linguísticas e textuais-discursivas que conduzem ao humor. As propostas listadas aqui são apenas sugestões que, com adaptações, podem ser apresentadas a turmas de ensino fundamental ou médio, em turmas regulares ou de EJA, dependendo do aprofundamento que se deseje na análise e da maturidade dos alunos.

Esperamos, com essas propostas, colaborar com o ensino de Língua Portuguesa, articulando leitura, análise linguística e produção textual. Esperamos, também, que com atividades como essas os alunos se sintam estimulados a conhecer a obra de Luis Fernando Verissimo, um dos mais famosos autores brasileiros contemporâneos.

\section{Referências}

BOSI, A. Um conceito de humorismo. In: BOSI, A. Céu, inferno - ensaios de crítica literária e ideologia. São Paulo: Ática, 1988. p. 187-191.

CANDIDO, A. et al. A crônica: o gênero, sua fixação e suas transformações no Brasil. Campinas. Ed. da Unicamp; Rio de Janeiro: Fundação Casa de Rui

Barbosa, $1992 . \quad$ Disponível em
https://pt.scribd.com/document/362492686/A-Cronica-o-Genero-suaFixacao-e-Suas-Transformacoes-No-Brasil. Acesso em 10 de janeiro de 2019.

CAVALCANTE, M. M. Referenciação: sobre as coisas ditas e não ditas. Fortaleza: UFC, 2011. 
CAVALCANTE, M. M. Os sentidos do texto. São Paulo: Contexto, 2012.

CAVALCANTE, M. M.; CUSTÓDIO FILHO, V.; BRITO, M. Coerência, referenciação e ensino. São Paulo: Cortez, 2014.

CIULLA E SILVA, A. Os processos de referência e suas funções discursivas: o universo literário dos contos. 2008. 205f. Tese (Doutorado em Linguística) Centro de Humanidades, Universidade Federal do Ceará, Fortaleza, 2008.

COLARMACO, M. Referenciação e construção de sentido nas fábulas de Monteiro Lobato e Esopo. 2014. 189f. Tese (Doutorado em Letras Vernáculas) - Faculdade de Letras, Universidade Federal do Rio de Janeiro, Rio de Janeiro, 2014.

KOCH, I. G. V. Desvendando os segredos do texto. São Paulo: Cortez, 2002.

KOCH, I. G. V. Referenciação e organização argumentativa. In: KOCH, I.; MORATO, E. M.; BENTES, A. C. (Org.). Referenciação e discurso. São Paulo: Contexto, 2005. p.7-34.

KOCH, I. G. V. As tramas do texto. Rio de Janeiro: Nova Fronteira, 2008.

KOCH, I. G. V.; MARCUSHI, L. A. Processos de Referenciação na produção discursiva. Revista Delta [online]. São Paulo, v. 14, s/p. 1998. Disponível em: http://www.scielo.br/scielo.php?pid=S0102-

44501998000300012\&script=sci_abstract\&tlng=pt. Acesso em: 10 de dezembro de 2018.

KONZEN, P. C. Ensaios Sobre a Arte da Palavra. Cascavel: Edunioeste, 2002.

MARCUSCHI, L. A. Produção textual, análise de gêneros e compreensão. São Paulo: Parábola, 2008.

POSSENTI, S. Os humores da língua. Campinas: Mercado das Letras, 1998.

POSSENTI, S. O humor e a língua. Ciência hoje. v.30, n. 176, p. 72-74, 2001. Disponível em: http://aescritanasentrelinhas.com.br/wpcontent/uploads/2009/02/o-humor-e-a-lingua-texto.pdf. Acesso em: 02 de janeiro de 2019.

POSSENTI, S. Humor, língua e discurso. São Paulo: Contexto, 2010.

PROPP, V. Comicidade e riso. São Paulo: Ática, 1992.

RITTER, L. C. B. Gênero discursivo crônica: um estudo do contexto de produção. V SIGET - Simpósio Internacional de Estudos de Gêneros Textuais. Agosto 2009. Disponível em: https://www.ucs.br/ucs/extensao/agenda/eventos/vsiget/portugues/anais/

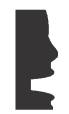


arquivos/genero discursivo cronica um estudo do contexto de produca o.pdf. Acesso em: 2 de janeiro de 2019.

SÁ, J. A crônica. 3. ed. São Paulo: Ática, 1987.

SANTOS, D. Z. A importância do conhecimento prévio para compreensão do humor na publicidade. 2004. 121f. dissertação (Mestrado em Letras Vernáculas) - Faculdade de Letras, Universidade Federal do Rio de Janeiro, Rio de Janeiro, 2004.

SANTOS, L. W. Os paradidáticos e o ensino de leitura no 19 grau. Dissertação (Mestrado em Letras Vernáculas) - Faculdade de Letras, Universidade Federal do Rio de Janeiro, Rio de Janeiro, 1994.

SANTOS, L. W.; CAVALCANTE, M. Referenciação: continuum anáfora-dêixis. Revista Intersecções, São Paulo, v. 12, n. 1, p. 224-246, Mai. 2014. Disponível em: http://www.portal.anchieta.br/revistas-elivros/interseccoes/pdf/interseccoes ano 7 numero 1.pdf. Acesso em 02 de janeiro de 2019.

SANTOS, L. W.; RICHE, R. C.; TEIXEIRA, C. S. Análise e produção de textos. São Paulo: Contexto, 2012.

TRAVAGLIA, L. C. Uma introdução ao estudo do humor pela linguística. D.E.L.T.A: Revista de Documentação de Estudos em Linguística Teórica e Aplicada. São Paulo, v. 6, n. 1, p. 55-82, 1990. Disponível em: http://www.ileel.ufu.br/travaglia/sistema/uploads/arquivos/artigo uma int roducao ao estudo\%20do humor pela linguistica.pdf. Acesso em 02 de janeiro de 2019. 